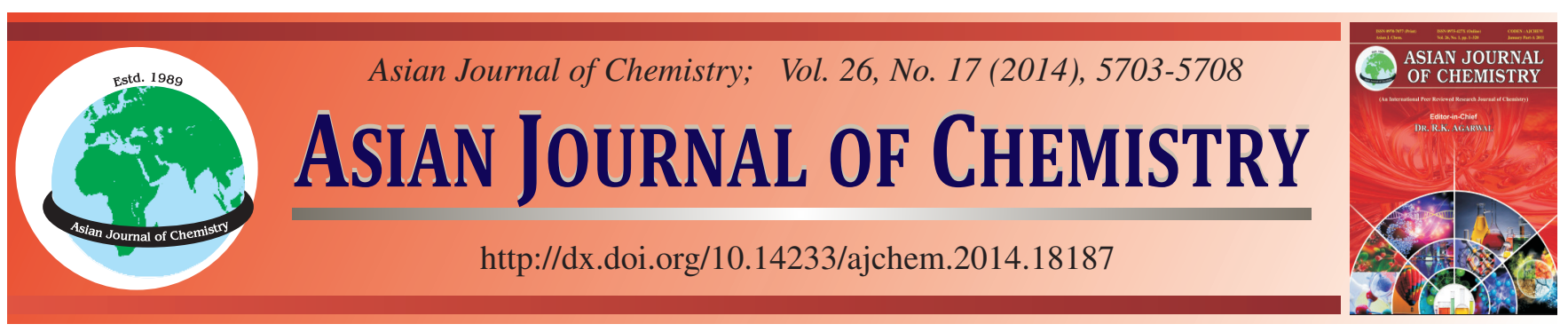

\title{
Waterborne Polyurethane Polymer Electrolytes Containing Poly(ethylene glycol) and Polydimethylsiloxane in Soft Segments $\dagger$
}

\author{
YuE-JiAO Li ${ }^{1,2, *}$, SHI CHEN ${ }^{1,2}$ and FenG Wu ${ }^{1,2}$
}

${ }^{1}$ Beijing Key Laboratory of Environmental Science and Engineering, School of Chemical Engineering and the Environment, Beijing Institute of Technology, Beijing 100081 P.R. China

${ }^{2}$ National Development Center for High Technology Green Material, Beijing 100081, P.R. China

*Corresponding author: E-mail: lyj@bit.edu.cn

\begin{abstract}
New waterborne polyurethane polymer electrolytes containing poly(ethylene glycol) and polydimethylsiloxane (PDMS) in the soft segments were designed and synthesized. The structure and performance of the electrolytes were characterized by Fourier transform infrared spectroscopy, differential scanning calorimetry, thermogravimetric analysis, electrochemical impedance spectroscopy and linear sweep voltammetry. The membranes exhibited good electrochemical stability. The thermal stability of the polymer electrolytes increased with increased content of polydimethylsiloxane. The conductivity results indicated that the incorporation of polydimethylsiloxane up to a certain amount (17 wt \%) increased the ionic conductivity, but further addition decreased the conductivity. Gel polymer electrolytes were obtained by immersing polymer membranes in $1 \mathrm{M} \mathrm{LiTFSI/DMC+EC} \mathrm{(DMC:EC}=1: 1$ by weight) for different durations. These electrolytes possessed good ionic conductivity, i.e., ca. $2.52 \times 10^{-3} \mathrm{~S} / \mathrm{cm}$ with a swollen percentage of $130 \mathrm{wt} \%$ at room temperature.
\end{abstract}

Keywords: Polymer electrolyte, Waterborne polyurethane, Polydimethylsiloxane, Copolymerization, Ionic conductivity.

\section{INTRODUCTION}

Polymer electrolytes have potential application in a variety of electrochemical devices, such as high-energy-density batteries, fuel cells and sensors. Lithium polymer batteries using polymer electrolytes are widely studied ${ }^{1-4}$. Waterborne polyurethane (WPU) materials are also attracting considerable interest because of the lack of solvent vapor problems and their special phase-separation structure that favours ionic conduction $^{5-8}$. These materials have been applied in a number of fields, particularly as polymer electrolytes in primary and secondary high-energy-density lithium batteries. Solid polymer electrolytes based on poly(ethylene glycol) (PEO) segmental WPU for lithium batteries have been synthesized ${ }^{9-12}$. However, the applications of these electrolyte systems are hindered by their low ionic conductivity at room temperature.

Polydimethylsiloxane (PDMS) has many applications because of its unique properties, including low surface tension, unique flexibility, low glass transition temperature and high temperature stability ${ }^{13-18}$. These properties mainly arise from the natural structure of PDMS comprising inorganic Si-O bonds and organic graft $\mathrm{CH}_{3}$ groups ${ }^{19-22}$. The excellent flexibility of PDMS can be introduced into a polymer matrix to improve its ionic conductivity at low temperatures. Therefore, PDMS can serve as a component of a good ion-conducting polymer electrolyte. Some attempts have been made to modify the structure of the polyurethane (PU) polymer matrix by PDMS to improve its electrical, electrochemical and mechanical properties. The ionic conductivity of a polymer electrolyte based on polyurethane and PDMS blends is enhanced compared with pure polyurethane ${ }^{23}$. The copolymerization approach has been used to synthesize polyurethane block copolymers containing double soft segments of PEO and PDMS and this electrolyte system has good thermal stability and high ionic conductivity ${ }^{24,25}$. The ambient ionic conductivity of a novel network polymer electrolyte based on PDMS is $7.9 \times 10^{-5} \mathrm{~S} / \mathrm{cm}^{26}$. Some PDMS-modified WPU copolymers have also been synthesized and their properties have been investigated for other applications ${ }^{27-29}$. However, reports on the effects of the introduction of PDMS into WPU polymer electrolytes are few.

Our group has attempted to introduce PDMS into WPU as well as synthesize new WPU polymer electrolytes containing PEO and PDMS in the soft segments. The primary research results have been already published ${ }^{13}$. To gain systematic knowledge on the effects of PDMS on the properties of WPU, 
an introduction on the new polymer electrolyte is provided in this paper. The synthesis, structure analysis and performance tests are reported. The effects of the PDMS content on the structural, thermal and electrochemical properties of the electrolytes are also discussed.

\section{EXPERIMENTAL}

Poly(ethylene glycol) (PEO) $(\mathrm{Mw}=2000$; Alfa Aesar), used as the soft segment, was dried at $75{ }^{\circ} \mathrm{C}$ for $72 \mathrm{~h}$ in a vacuum. The other soft segment, PDMS (hydroxy terminated, viscosity $=90-150$ cSt; Aldrich), was immersed in 4 A molecular sieves for $24 \mathrm{~h}$. IPDI (Alfa Aesar) and DMPA (Alfa Aesar), both used as hard segments, were vacuum dried at $80{ }^{\circ} \mathrm{C}$ for $24 \mathrm{~h}$. LiTFSI (99 \%; 3M Inc.) was vacuum dried at $140{ }^{\circ} \mathrm{C}$ for $12 \mathrm{~h}$. N,N-Dimethylformamide (DMF) was immersed in $4 \AA$ molecular sieves for more than 1 week before use. All other chemicals were used as received.

Preparation of WPU copolymers: All WPU copolymers were synthesized by a two-step addition reaction according to Scheme-I. The mixture of PEO and PDMS (PDMS weight ratios $=0,5,9,17,23,35,41$ and $55 \%$ ) was used as the soft segment. To synthesize the copolymer, 1 mol of PEO-PDMS mixture and $1 \mathrm{~mol}$ of DMPA were placed in a reactor and heated to $75^{\circ} \mathrm{C}$. Then, $3 \mathrm{~mol}$ of IPDI and di- $n$-butyltin dilaurate catalyst were added and allowed to react at $90{ }^{\circ} \mathrm{C}$ under nitrogen atmosphere for $4 \mathrm{~h}$ until half the $\mathrm{NCO}$ residue value of IPDI was achieved. The change in NCO value during the prepolymerization was determined by a standard dibutylamine back-titration method ${ }^{30}$. The prepolymer was then cooled to $70{ }^{\circ} \mathrm{C}$ and neutralized with lithium hydroxide $(\mathrm{LiOH})$. The stoichiometric ratio of $\mathrm{LiOH}$ to $\mathrm{COOH}$ was 1.0 . The prepolymer aqueous dispersion was obtained by adding water dropwise during the chain-extension process with aqueous EDA for $2 \mathrm{~h}$. The final aqueous dispersion was diluted to 30 wt $\%$.
Solid polymer electrolyte membrane casting: An aqueous polymer dispersion was used for membrane casting. Different weight ratios of LiTFSI (5, 10, 15, 20 and $25 \mathrm{~g} / 100 \mathrm{~g}$ WPU) were added dropwise to the polymer aqueous dispersion with stirring. The membranes from the solvent evaporation method were obtained by casting the aqueous dispersion on a PTFE plate, followed by drying at $75^{\circ} \mathrm{C}$ for $72 \mathrm{~h}$ in a vacuum. Then, the membranes were removed and placed in a glove box for further drying. The samples were named "Cm-n", where $\mathrm{m}$ was the PDMS content in the PEO-PDMS mixture and $\mathrm{n}$ was the LiTFSI content in the polymer electrolyte (e.g., C17-20 means $17 \mathrm{wt} \%$ PDMS and $20 \mathrm{wt} \%$ LiTFSI).

Gel polymer electrolyte membrane casting: Polymer membranes were prepared by casting the aqueous polymer dispersion on a PTFE plate at $75^{\circ} \mathrm{C}$ for $72 \mathrm{~h}$ in a vacuum. To prepare the gel polymer electrolytes, the polymer membranes were immersed in $1 \mathrm{M} \mathrm{LiTFSI} /(\mathrm{DMC}+\mathrm{EC})(\mathrm{DMC}: \mathrm{EC}=1: 1$ by weight) solution for different durations and various contents of the solution were obtained. The solution swollen percentage of the polymer membrane was defined as:

$$
\mathrm{SP}(\%)=\frac{\mathrm{W}-\mathrm{W}_{0}}{\mathrm{~W}_{0}}
$$

where $\mathrm{W}$ is the weight of the gel polymer membrane and $\mathrm{W}_{0}$ is the original weight of the dry polymer membrane.

Characterization: The Fourier transform infrared (FT-IR) spectra of the polymer system were recorded on a Bruker EQUINOX55 FT-IR spectrometer between 4000 and $500 \mathrm{~cm}^{-1}$. The solid sample was mixed with dry $\mathrm{KBr}$ for infrared (IR) spectroscopic measurement. The melting point $\left(\mathrm{T}_{\mathrm{m}}\right)$, melting enthalpy $(\Delta \mathrm{H})$ and glass transition temperature $\left(\mathrm{T}_{\mathrm{g}}\right)$ of the polymer matrix were determined on a DSC Q100 differential scanning calorimeter (TA Instruments, USA) by sealing about $10 \mathrm{mg}$ of the sample in an aluminum pan. The pan and sample were first cooled to about $-80{ }^{\circ} \mathrm{C}$ under nitrogen atmosphere and
$\mathrm{HO}+\mathrm{CH}_{2} \mathrm{CH}_{2} \mathrm{O} \underset{\mathrm{n}}{-} \mathrm{OH}+\mathrm{HO}-\left(\left.\right|_{\mathrm{CH}_{3}} ^{\mathrm{Si}_{3}} \mathrm{O}+\frac{\mathrm{H}_{\mathrm{n}}}{\mathrm{H}} \mathrm{H}+\right.$

PEO

PDMS<smiles>CC(CO)(CO)C(=O)O</smiles>

DMPA<smiles>CC1(C)CC([N+]=O)CC(C)(CN=O)C1</smiles>

IPDI

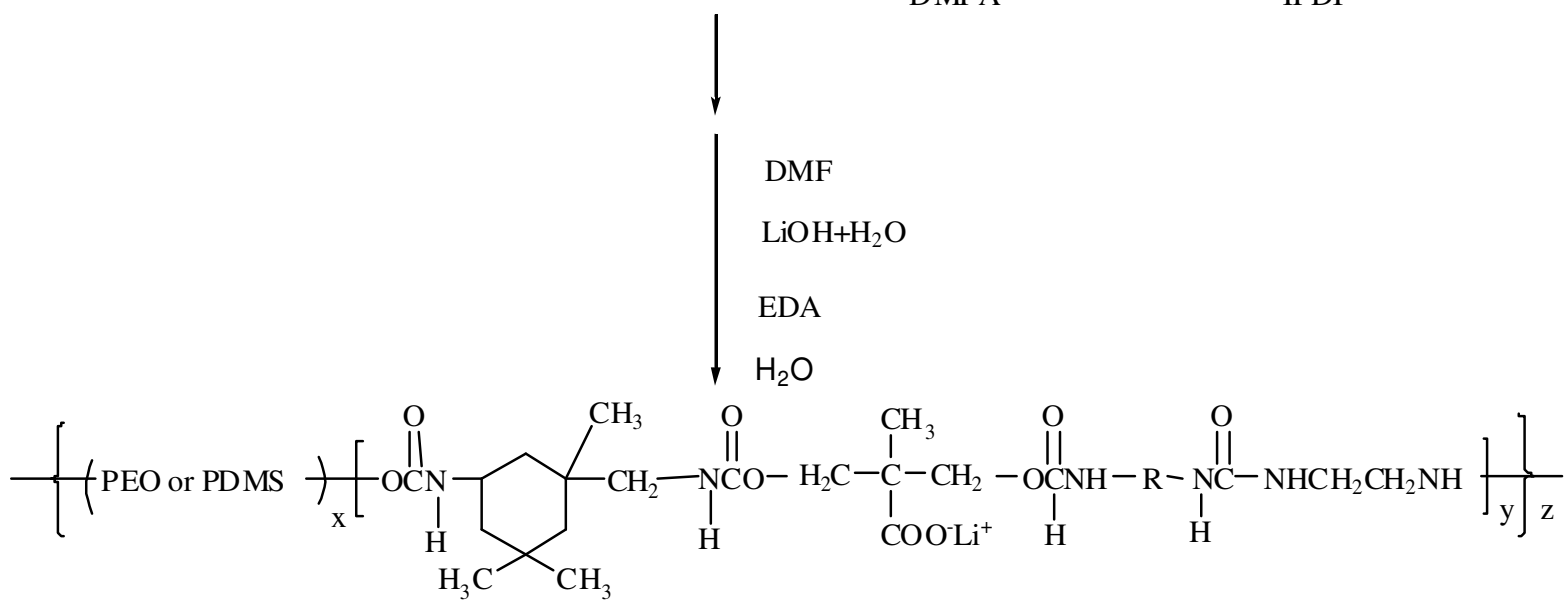

Soft segment

Hard segment

Scheme-I: Preparation process for PDMS modified WPU polymer 
then heated to $150{ }^{\circ} \mathrm{C}$ at a rate of $5^{\circ} \mathrm{C} / \mathrm{min}$. Thermal stability data were obtained using a thermogravimetric analysis (TGA) system (DSC Q50, TA, USA) from 0-800 ${ }^{\circ} \mathrm{C}$ under nitrogen atmosphere at a heating rate of $20^{\circ} \mathrm{C} / \mathrm{min}$. The ionic conductivity $(\sigma)$ of the polymer electrolyte membrane was measured by electrochemical impedance spectroscopy in a hermetic cell with stainless steel blocking electrodes. The impedance tests were carried out over the frequency range from $1-100 \mathrm{KHz}$ at an amplitude of $5 \mathrm{mV}$. The membrane was sandwiched between two pretreated stainless steel disk electrodes (area $=0.9503$ $\mathrm{cm}^{2}$ ). The measurements were conducted at controlled constant temperature ranging from 30 to $80{ }^{\circ} \mathrm{C}$ The sample was thermally equilibrated at each temperature for at least $1 \mathrm{~h}$ prior to measurement. The ionic conductivity of the polymer electrolyte was calculated based on the following equation:

$$
\sigma=\frac{1}{\mathrm{R}} \times \frac{1}{\mathrm{~A}}
$$

where $\sigma$ is the ionic conductivity, $\mathrm{R}$ is the bulk resistance, 1 is the thickness of the polymer electrolyte and A is the area of the stainless steel electrode. Linear sweep voltammetry (LSV) experiments were performed to investigate the electrochemical stability of the electrolytes. A three-electrode cell, with a stainless steel working electrode as well as lithium counter and reference electrodes, was used. All LSV experiments were carried out from 1.5-7.0 V versus $\mathrm{Li}$ at a sweep rate of $10 \mathrm{mV} / \mathrm{s}$. Both ionic conductivity and electrochemical stability were measured using a CHI604c electrochemical workstation (Chenhua Instrument Company, Shanghai).

\section{RESULTS AND DISCUSSION}

Structural analysis: A series of WPU polymer electrolytes containing PEO and PDMS in the soft segments (WPEU10, C5-10, C9-10, C17-10, C23-10, C35-10, C41-10 and C4510) was prepared. Polymer electrolyte membranes were prepared by varying the weight ratio of PEO/PDMS and maintaining the salt concentration at $10 \mathrm{wt} \%$.

Fig. 1 shows the FT-IR spectra of the samples. The characteristic NCO peak at $2200 \mathrm{~cm}^{-1}$ disappears, indicating the complete conversion of isocyanate to polyurethane. The absorption peaks around $3450\left(\mathrm{~N}-\mathrm{H}\right.$ stretching), $2950\left(-\mathrm{CH}_{2}\right.$ stretching) and 1640 (H-bonded urea $\mathrm{C}=\mathrm{O}$ stretching $\mathrm{cm}^{-1}$ are assigned to the urea linkage. The peaks at $1720 \mathrm{~cm}^{-1}$ (urethane $\mathrm{C}=\mathrm{O}$ stretching) and $1080 \mathrm{~cm}^{-1}$ (C-O-C stretching) confirm the formation of the urethane linkage. The peaks at 1030 and 1100 $\mathrm{cm}^{-1}$ (Si-O-Si stretching) are associated with PDMS, whereas the peaks at $1260\left(\mathrm{CH}_{3}\right.$ in $\mathrm{Si}-\mathrm{CH}_{3}$ symmetry bending $)$ and 800 $\left(\mathrm{CH}_{3}-\mathrm{Si}\right.$ rocking $) \mathrm{cm}^{-1}$ are related to the methyl group. These peaks are specifically present in the main chain of the PDMS soft segment, which indicates the incorporation of PDMS into WPU. The intensity of the peaks related to $\mathrm{CH}_{3}$ and Si-O-Si simultaneously increases with increased PDMS content.

Fig. 2 shows the FT-IR spectrum of the carbonyl stretching region ranging from $1800-1400 \mathrm{~cm}^{-1}$ for the polymer system with different PDMS contents. Four main peaks of the carbonyl region are $\operatorname{shown}^{10}:$ (1) the peak centered at around $1720 \mathrm{~cm}^{-}$ ${ }^{1}$ attributed to the stretching of the free urethane carbonyl group (2) the peak at $1630 \mathrm{~cm}^{-1}$ assigned to the H-bonding urethane carbonyl group, also called H-bonding in the disordered

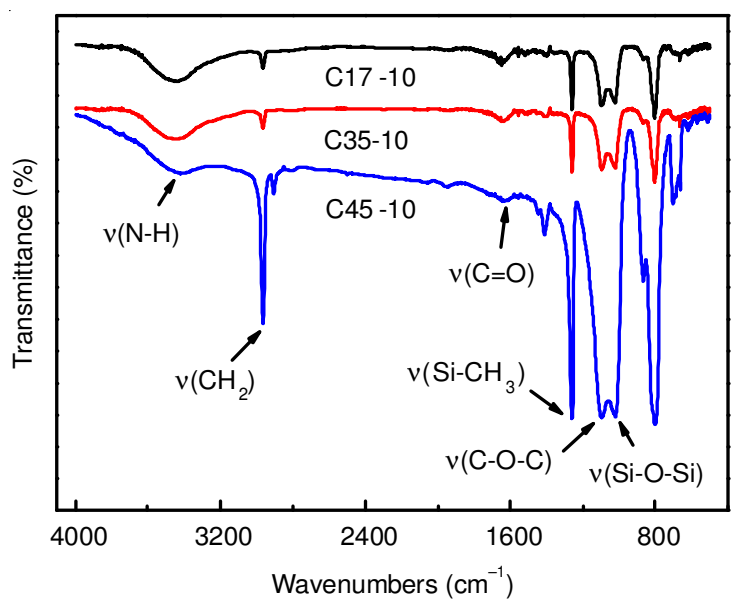

Fig. 1. FT-IR spectra for electrolyte system with different PDMS content

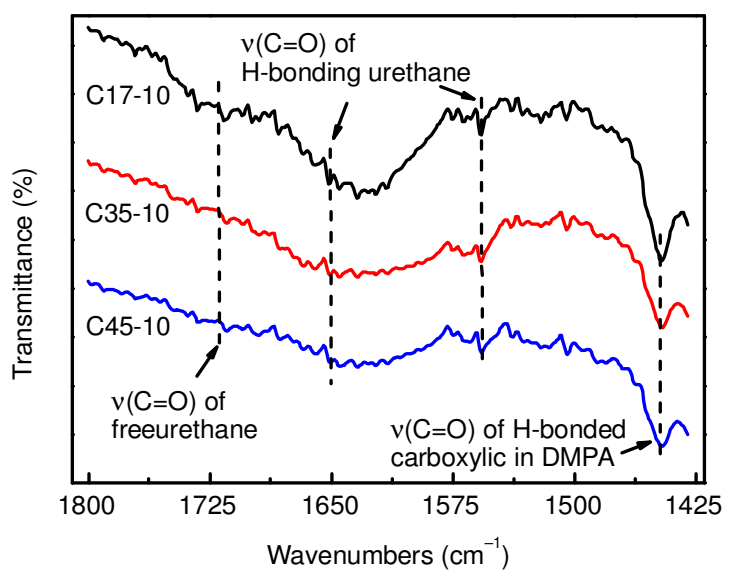

Fig. 2. FT-IR spectra of carbonyl stretching for electrolyte system with different PDMS

regions, which originates from the urethane linkage of the interfacial regions or "dissolved" in the soft phase (3) the peak at $1550 \mathrm{~cm}^{-1}$ that is the stronger H-bonding in the ordered or crystalline regions and (4) the peak centered at $1450 \mathrm{~cm}^{-1}$ assigned to the stretching of the H-bonded carboxylic carbonyl group from the DMPA unit. The intensities of the free urethane carbonyl and $\mathrm{H}$-bonding urethane carbonyl peaks are strong at low amounts of PDMS (e.g., C17-10). However, the intensities of these peaks decrease with increased PDMS content. This observation may be due to the decreased urethane content in the polymer matrix.

Thermal analysis: Fig. 3 shows the DSC curves of the electrolytes with different PDMS contents. Thermal data including the melting temperature $\left(\mathrm{T}_{\mathrm{m}}\right)$, melting enthalpy $(\Delta \mathrm{H})$ and glass transition temperature $\left(\mathrm{T}_{\mathrm{g}}\right)$ are listed in Table- 1 .

The glass transition temperature of sample WPEU-10 containing PEO in its soft segment is about $-42^{\circ} \mathrm{C}$, whereas those of the WPUs containing PEO and PDMS in their soft segments are lower. Sample C35-10 has $\mathrm{T}_{\mathrm{g}} \approx 47{ }^{\circ} \mathrm{C}$, which decreases with increased PDMS content; thus, the introduction of PDMS decreases the electrolyte $\mathrm{T}_{\mathrm{g}}$. The DSC curves also show that $\mathrm{T}_{\mathrm{m}}$ of the electrolyte system is around $30^{\circ} \mathrm{C}$. The addition of PDMS to the polymer matrix continuously reduces the polymer $\mathrm{T}_{\mathrm{m}}$, which changes from $37.4-31.5^{\circ} \mathrm{C}$ after the addition of 23 wt \% PDMS. The crystallinity of the host polymer decreases as indicated by the enthalpy change. This 


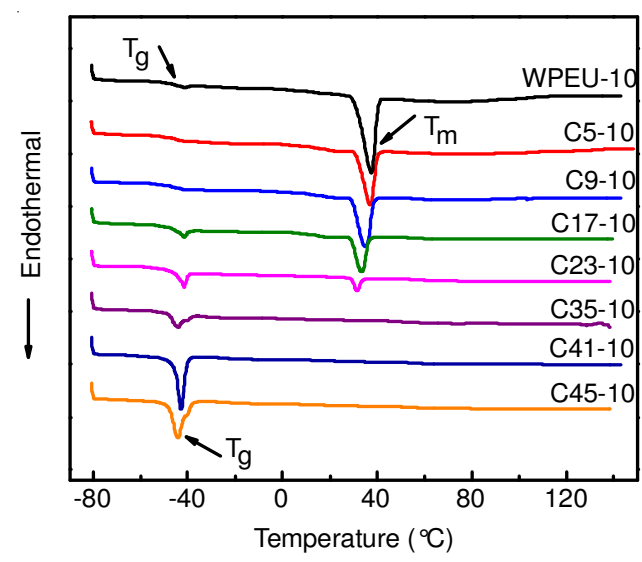

Fig. 3. DSC diagrams for electrolyte system with different PDMS content

\begin{tabular}{cccccc}
\multicolumn{7}{c}{ TABLE-1 } \\
\multicolumn{7}{c}{ THERMAL PROPERTIES OF VARIOUS ELECTROLYTES } \\
\hline \multirow{2}{*}{ Sample } & $\begin{array}{c}\text { PDMS } \\
\text { content }\end{array}$ & $\begin{array}{c}\mathrm{T}_{\mathrm{g}} \\
\left({ }^{\circ} \mathrm{C}\right)\end{array}$ & $\begin{array}{c}\mathrm{T}_{\mathrm{m}} \\
\left({ }^{\circ} \mathrm{C}\right)\end{array}$ & $\begin{array}{c}\Delta \mathrm{H} \\
(\mathrm{J} / \mathrm{g})\end{array}$ & $\begin{array}{c}\mathrm{T}_{5} \\
\left({ }^{\circ} \mathrm{C}\right)\end{array}$ \\
\hline WPEU & 0 & -41.7 & 37.4 & 28.7 & 235 \\
C5-10 & 5 & -42.6 & 37.0 & 19.0 & 236 \\
C9-10 & 9 & -43.8 & 35.1 & 18.3 & 236 \\
C17-10 & 17 & -45.0 & 33.4 & 10.7 & 238 \\
C23-10 & 23 & -45.9 & 31.5 & 2.6 & 240 \\
C35-10 & 35 & -47.3 & - & - & 242 \\
C41-10 & 41 & -47.8 & - & - & 248 \\
C45-10 & 45 & -48.3 & - & - & 260 \\
\hline
\end{tabular}

$\mathrm{T}_{\mathrm{g}}$ : Glass transition temperature, $\mathrm{T}_{\mathrm{m}}$ : Melting temperature, $\Delta \mathrm{H}$, melting enthalpy, $\mathrm{T}_{5}: 5 \%$ weight loss temperature; -: not observed.

finding is possibly due to the formation of more amorphous domains with the introduction of PDMS into the polymer. Consequently, the degree of crystallization of the polymer matrix decreases with increased PDMS content. This phenonemon stabilizes the amorphous structure of the polymer electrolyte and enhances the ionic conductivity.

The weight loss behaviours were investigated by TGA scanning from $0-800^{\circ} \mathrm{C}$. The TGA thermograms of the polymer electrolytes with various PDMS contents are shown in Fig. 4. All degradation temperatures were measured onset and the results are listed in Table-1. Sample WPEU-10 exhibits gradual weight loss starting at about $235^{\circ} \mathrm{C}$, with a $5 \%$ residual weight at $450^{\circ} \mathrm{C}$. However, the addition of PDMS to WPU contributes to the increase in the initial $5 \%$ weight loss temperature $\left(\mathrm{T}_{5}\right)$ of the electrolytes. The thermal stability of WPU improves with increased PDMS content because of the higher thermal durability of PDMS than PEO. The decomposition of sample C45-10 starts at about $260{ }^{\circ} \mathrm{C}$, with a residual weight of about $5 \%$ at $500{ }^{\circ} \mathrm{C}$. Compared with WPEU-10, $\mathrm{T}_{5}$ of C45-10 increases at $25^{\circ} \mathrm{C}$. All samples are also found to be stable from ambient temperature to $236^{\circ} \mathrm{C}$, with a very low weight loss of about $5 \%$. Hence, the WPU polymer electrolytes containing PEO and PDMS in their soft segments exhibit higher initial decomposition temperature than WPEU. This finding illustrates that the addition of PDMS improves the thermal stability of the polymer system and that the optimum temperature up to which this polymer electrolyte can be effectively used is $236^{\circ} \mathrm{C}$.

Ionic conductivity: Fig. 5 shows the Arrhenius relationship between the conductivity and temperature for the

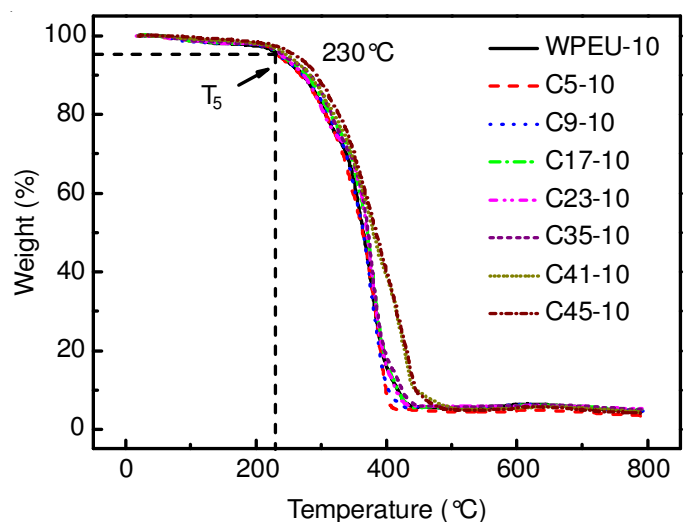

Fig. 4. TGA curves for electrolyte system with different PDMS content

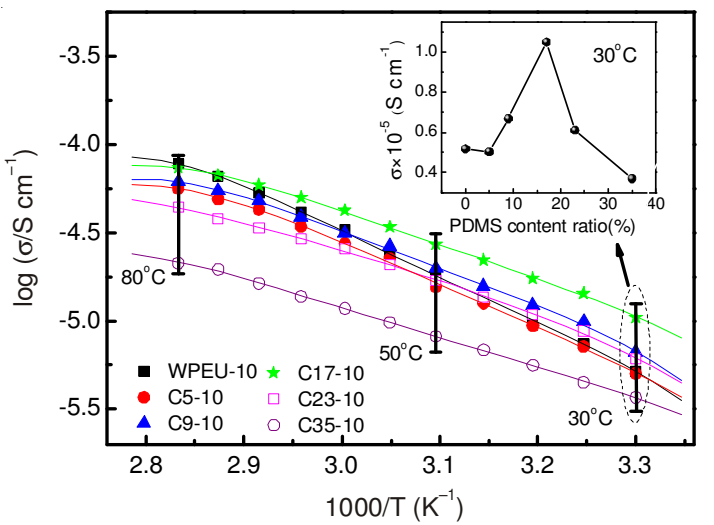

Fig. 5. Arrhenius relationship between conductivity and temperature for electrolyte system with different PDMS content, where the inset one is the relationship between conductivity and PDMS content at $30^{\circ} \mathrm{C}$

electrolytes with different PDMS contents and fixed salt concentration of $10 \mathrm{wt} \%$. The conductivity values increase for all compositions with increased temperature. The high temperature does not only benefit the movement of carrier ions, but also causes polymer expansion that promotes ionic conductivity $^{31}$. The non-linearity of the Arrhenius plots indicates that the ion transport in the electrolyte depends on the polymer segmental motion. Thus, the results may be explained by the Vogel-Tasman-Fulcher (VTF) relation, which describes the transport properties in a viscous matrix. The inset of Fig. 5 shows the PDMS content dependence of the conductivity at $30{ }^{\circ} \mathrm{C}$. The ionic conductivity initially decreases with the addition of $5 \mathrm{wt} \%$ PDMS, but increases with further addition of PDMS. The ionic conductivity reaches the maximum of $1.05 \times 10^{-5} \mathrm{~S} / \mathrm{cm}$ at a PDMS content of $17 \mathrm{wt} \%$ and then decreases. This change trend in conductivity can be attributed to the presence of PDMS. An appropriate content of PDMS can significantly enhance the motion of the polymer segment and result in increased ionic conductivity.

Fig. 6 shows the VTF relationship between the conductivity and temperature for the electrolytes with different PDMS contents. The ionic transport behaviour corresponds to the VTF model given by eqn. 3 , as justified by the linear relation between $\ln \sigma \mathrm{T}^{12}$ and $1 /\left(\mathrm{T}-\mathrm{T}_{0}\right)$ in Fig. 6 .

$$
\sigma(T)=A T^{-1 / 2} \exp \left(\frac{-B}{T-T_{0}}\right)
$$




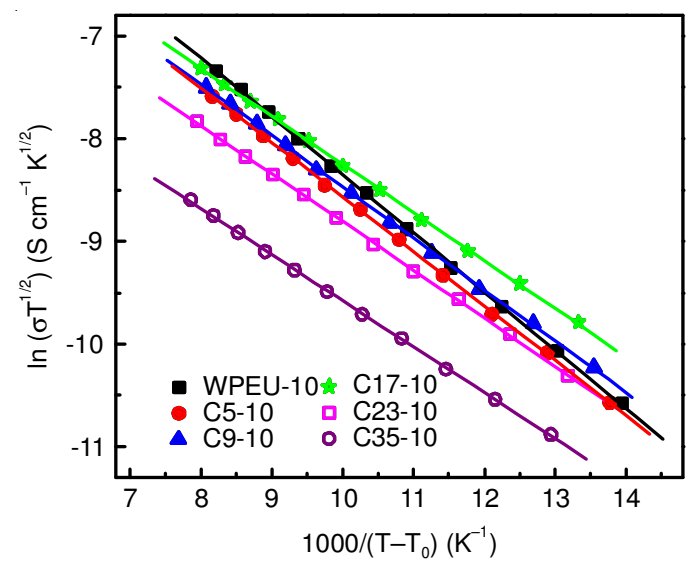

Fig. 6. VTF relationship between conductivity and temperature for electrolyte system with different PDMS content

The VTF relationship also implies that the temperature dependence of the ionic conductivity can be described by the VTF model instead of the Arrhenius model. Thus, the transfer of carrier ions mainly occurs in the amorphous domains of the polymer chain.

The dependence of the conductivity on the salt concentration is illustrated in Fig. 7 and the plots obey the VTF model. The ionic conductivity increases with increased salt content but reaches the maximum of $1.49 \times 10^{-5} \mathrm{~S} / \mathrm{cm}$ at $30{ }^{\circ} \mathrm{C}$ with 20 wt $\%$ salt content and then decreases thereafter. This behaviour is mainly attributed to the increased charge carrier concentration and ion mobility at low salt content, as well as the strong electrostatic environment of TFSI ${ }^{-}$ions at high salt content.

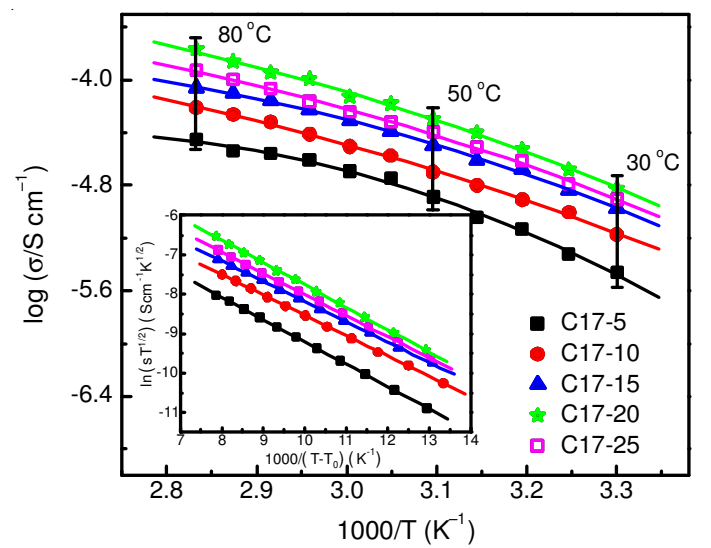

Fig. 7. Arrhenius relationship between conductivity and temperature for electrolyte system with different LiTFSI content, where the inset one is VTF relationship

The gel polymer electrolyte membrane was prepared by dipping the polymer membrane C17 (17wt \% PDMS) into $1 \mathrm{MLiTFSI} /(\mathrm{DMC}+\mathrm{EC})(\mathrm{DMC}: \mathrm{EC}=1: 1$ by weight $)$ solution. The swollen rate and saturated swollen percentage can be obtained from the slope and plateau of the curves, respectively. The weight of the gel polymer membrane consisting of the polymer matrix and absorbed electrolyte solution was measured before and after immersion. Fig. 8 shows that the initial swelling of the membrane rapidly occurs in the first $20 \mathrm{~min}$, indicating quick absorption of the solution by the polymer. The absorption of the $\mathrm{C} 17$ membrane almost reaches saturation after $2 \mathrm{~h}$ and the electrolyte content in the overall weight

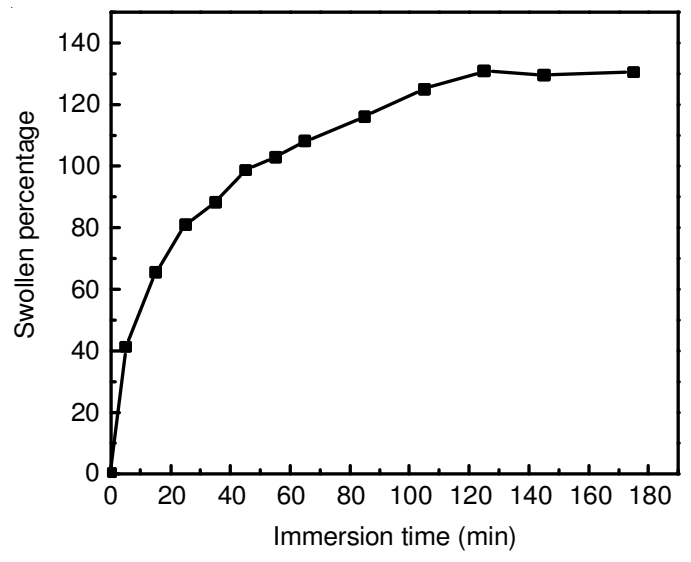

Fig. 8. Relationship between swelling percentage and immersion time for C17 membrane

of the polymer is $130 \mathrm{wt} \%$. This finding demonstrates that this polymer matrix possesses excellent solvent resistance and easily forms a gel polymer electrolyte.

The Arrhenius relationship between the conductivity and temperature of the gel polymer electrolytes with different LiTFSI/(DMC+EC) contents is shown in Fig. 9. The ion conductivity of the sample with low LiTFSI/(DMC+EC) content (50 wt \%) is mainly dominated by the polymer chain movements and thus exhibits a non-linear Arrhenius plot. With increased LiTFSI/(DMC+EC) content (100 and $130 \mathrm{wt} \%)$, the Arrhenius plots of the samples become linear. This result may be due to the construction of a local effective pathway in the liquid phase for ionic conduction. The ionic conductivity significantly increases with increased swollen percentage. This trend between the solution absorption and ionic conductivity is a general one and can be attributed to the enhanced ionic mobility caused by the increased number of carrier ions. The ionic conductivity of the gel polymer electrolytes with different swollen percentages at room temperature is $2.69 \times 10^{-5} \mathrm{~S} / \mathrm{cm}$ (50 wt \%), $1.19 \times 10^{-3} \mathrm{~S} / \mathrm{cm}(100 \mathrm{wt} \%)$ and $2.52 \times 10^{-3} \mathrm{~S} / \mathrm{cm}$ (130 wt \%).

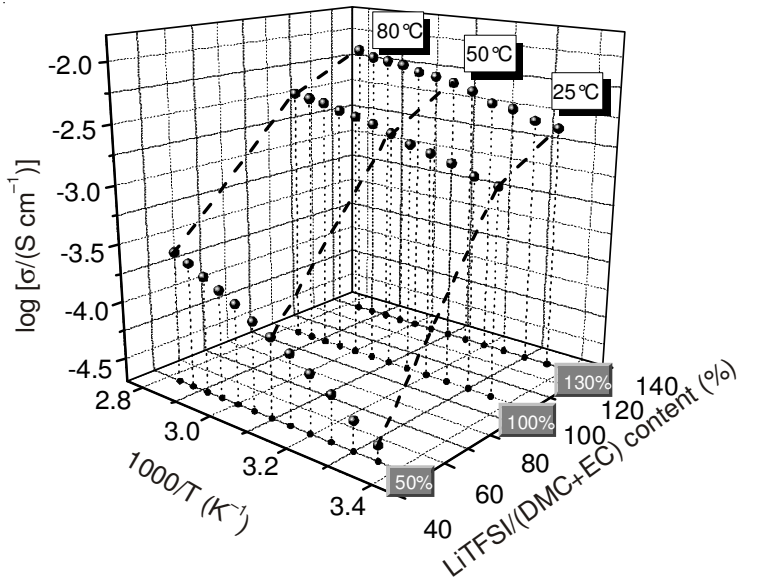

Fig. 9. Arrhenius relationship between conductivity and temperature of gel polymer electrolytes with different LiTFSI/(DMC+EC) content

Electrochemical stability analysis: The electrochemical stability window of the polymer electrolyte was generally determined by LSV. The onset of current at a high positive voltage, which was the upper limit of the electrolyte stability 
range, was assumed to result from a decomposition process associated with the electrode ${ }^{32}$. Fig. 10 shows the currentvoltage response of the WPU polymer electrolytes at room temperature.

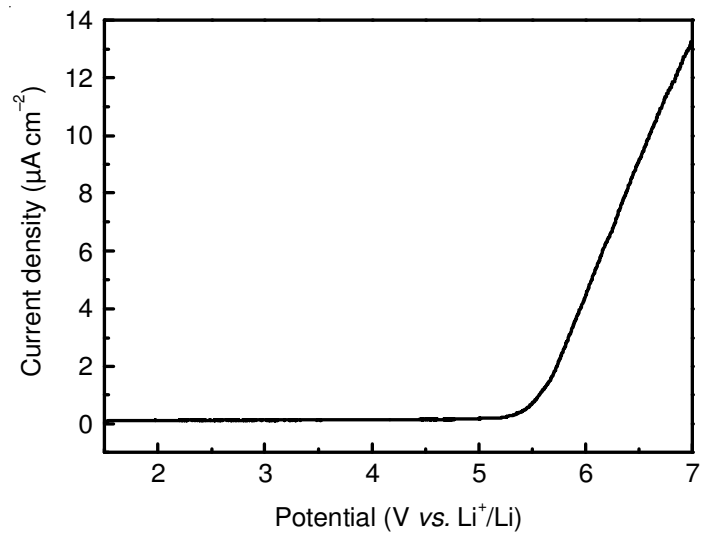

Fig. 10. Linear sweep voltammetry curve for sample C17-25

The potential was scanned from 1.5-7.0 V (versus $\mathrm{Li} / \mathrm{Li}^{+}$) at a sweep rate of $10 \mathrm{mV} / \mathrm{s}$. Without PDMS, the electrochemical stability window of the sample WPEU-10 is $4.0 \mathrm{~V}$. The incorporation of PDMS significantly affects the electrochemical stability of the electrolytes. The current response of sample C9-10 is negligible below $5.6 \mathrm{~V}$, indicating that no component in this potential region decomposes from the open circuit potential to $5.6 \mathrm{~V}$. Thus, this electrolyte system is electrochemically stable up to $5.6 \mathrm{~V}$. With increased PDMS from $9-23 \%$, the electrochemical stability window decreases but is maintained above $4.8 \mathrm{~V}$. Therefore, the addition of PMDS can improve the electrochemical stability of WPU electrolyte and the electrolyte system can be used in rechargeable lithium-ion batteries.

\section{Conclusion}

A new type of polymer electrolytes based on WPU copolymers containing poly(ethylene glycol) and PDMS in the soft segments was designed and synthesized. These polymer electrolytes have high ionic conductivity as well as good electrochemical and thermal stabilities. Analyses indicate that the introduction of PDMS can effectively decrease the crystallinity of the host polymer, which benefits polymer segment movement and results in increased ionic conductivity. The room-temperature ionic conductivity of the gel polymer electrolyte with a swollen percentage of $130 \mathrm{wt} \%$ reaches up to $2.52 \times 10^{-3} \mathrm{~S} / \mathrm{cm}$. Thus, the WPU polymer electrolytes are promising electrolytes for practical applications in lithium batteries.

\section{ACKNOWLEDGEMENTS}

This work was supported by the National Key Program for Basic Research of China (No. 2009CB220100), National
High-tech 863 Key Program (No. 2011AA11A235) and Basic Research Fund of Beijing Institute of Technology (No. 3100012211111).

\section{REFERENCES}

1. Y.J. Wang and D. Kim, J. Power Sources, 166, 202 (2007).

2. M.M. Nasef and H. Saidi, Mater. Chem. Phys., 99, 361 (2006).

3. Y.H. Ding, P. Zhang, Z.L. Long, Y. Jiang, F. Xu and W. Di, J. Membr. Sci., 329, 56 (2009).

4. H. Li, X.T. Ma, J.L. Shi, Z.K. Yao, B.K. Zhu and L.P. Zhu, Electrochim. Acta, 56, 2641 (2011).

5. H.X. Pan and D. Chen, Rem. J., 79, 687 (2009).

6. C.C. Santos, M.C. Delpech and F.M.B. Coutinho, J. Mater. Sci., 44, 1317 (2009).

7. A.V. Raghu, Y.R. Lee, H.M. Jeong and C.M. Shin, Macromol. Chem. Phys., 209, 2487 (2008).

8. X.D. Cao, H. Dong and C.M. Li, Biomacromolecules, 8, 899 (2007).

9. T.T. Cheng and T.C. Wen, J. Electroanal. Chem., 459, 99 (1998).

10. T.C. Wen, Y.J. Wang, T.T. Cheng and C.H. Yang, Polymer, 40, 3979 (1999).

11. T.C. Wen, S.S. Luo and C.H. Yang, Polymer, 41, 6755 (2000).

12. H.L. Wang, A. Gopalan and T.C. Wen, Mater. Chem. Phys., 82, 793 (2003).

13. W. Choi, R. Padsalgikar, T. Choi, J. Weksler, A. Padsalgikar and J. Runt, Polymer, 50, 2320 (2009).

14. C.H. Lee, J.R. Chen, H.W. Shiu, K.S. Ho, S.D. Wu, K.H. Hsieh and Y.Z. Wang, Proc. $6^{\text {th }}$ International Conference on Full Cell Science, Engineering and Technology, p. 951 (2008).

15. J.P. Esquivel, N. Sabate, A. Tarancon, N. Torres-Herrero, D. Davila, J. Santander, I. Gracia and C. Cane, J. Micromech. Microeng., 19, 065006 (2009).

16. Y.-A. Song, C. Batista, R. Sarpeshkar and J. Han, J. Power Sources, 183, 674 (2008).

17. J.Y. Lee, B. Bhattacharya, D.-W. Kim and J.-K. Park, J. Phys. Chem. C, 112, 12576 (2008)

18. J. Chang and J. Zen, Electrochem. Commun., 9, 2744 (2007).

19. M.G. Voronkvov, V.P. Mileshkevich and Y.A. Yuzhelevskii, The Siloxane Bond, Consultants Bureau: New York (1978).

20. C. Eaborn, Organosilicon Compounds, Butterworths: London (1960).

21. W. Noll, Chemistry and Technology of Silicones, Academic Press: New York (1968).

22. L.F. Wang, Q. Ji, T.E. Glass, T.C. Ward, J.E. McGrath, M. Muggli, G. Burns and U. Sorathia, Polymer, 41, 5083 (2000).

23. M. Shibata, T. Kobayashi, R. Yosomiya and M. Seki, Eur. Polym. J., 36, 485 (2000).

24. P.L. Kuo, W.J. Liang and C.L. Lin, Macromol. Chem. Phys., 203, 230 (2002).

25. C.L. Lin, H.M. Kao, R.R. Wu and P.L. Kuo, Macromolecules, 35, 3083 (2002).

26. Z.C. Zhang and S.B. Fang, Electrochim. Acta, 45, 2131 (2000).

27. M.S. Yen and P.Y. Tsai, J. Appl. Polym. Sci., 90, 233 (2003).

28. M.S. Yen, P.Y. Tsai and P.D. Hong, Colloids Surf. A, 279, 1 (2006).

29. G.Q. Fei, Y.D. Shen, H.H. Wang and Y. Shen, J. Appl. Polym. Sci., 102, 5538 (2006).

30. D.J. David and H.B. Staley, Analytical Chemistry of Polyurethane, Wiley-Interscience, New York (1969).

31. Z. Cui, Y. Xu, L. Zhu, J. Wang, Z. Xi and B. Zhu, J. Membr. Sci., 325, 957 (2008)

32. S. Slane and N. Salomon, J. Power Sources, 55, 7 (1995). 